\title{
Goals for the next millennium
}

The Arquivos Brasileiros de Cardiologia is a 50 year old medical journal and one of the most respected and influential in Latin America. It is the journal of the Brazilian Society of Cardiology (SBC) and its main purpose is to stimulate the scientific output of Brazil and to publish the results of this scientific investigation.

An editor must have a clear vision of the goal to be achieved by his or her journal. Thus, the foundation of our editorial philosophy rests on the peer review of original scientific manuscripts. Our main objective is to encourage Brazilian authors to write and submit their scientific findings to our Editorial Board. By doing so, we hope, to help scientists accomplish one of their major commitments: the diffusion of the results of their research.

The success of a journal, however, depends on its readers. In a survey conducted during the XIII World Congress on Cardiology, held in Rio de Janeiro in 1998, where almost 1500 cardiologists were interviewed, more than 70\% indicated that they read and approve of the Arquivos Brasileiros de Cardiologia. The original articles, which characterize this journal and are essential to our scientific development, along with review articles were the most appreciated features of the journal. Such a high approval rating is an indication that Brazilian cardiologists are receptive to our editorial philosophy.

In the September 1998 edition of our journal, the summaries of the Brazilian postgraduate theses were published, which accomplished multiple objectives. Besides acquainting Brazilian cardiologists with the formal system of postgraduate studies, it provided a panoramic view of the scientific output of this system, a view that did not exist even among the many agencies sponsoring scientific research. The continuation of the initiative of September 1998 will enable the Arquivos Brasileiros de Cardiologia to function as an indexer of Brazilian theses on cardiology. In addition, we hope to stimulate the publication of these theses, so that they will not be confined to the "gray" zone of unpublished literature. Encouraging these authors to submit their theses to our Editorial Board will certainly enhance the final efficiency of the output of our healthy postgraduate system.

To provide better review articles for continuing medical education, we have reserved a significant part of our journal for those professionals who are experts in their fields. These experts will provide review articles on areas of greatest relevance in cardiology. This section, called State of the Art, is intended to be a sophisticated source of cutting edge cardiology.

The on-line publication of our journal on the Internet, done properly and with efficency, will significantly enhance access to the journal as well as its international exposure.
The projectSCIELO (Scientific Electronic Library On-line), a partnership between FAPESP (a foundation that supports research in São Paulo) and BIREME (a Latin American and Caribbean center for information on health sciences), may allow rapid publication of our journal electronically.

Critical analysis of scientific and technological policies is currently necessary not only for the government but also for well-organized societies. Quantitative systems for analysis of scientific output have been developed in the last decades to provide information on the scientific dynamics of a country or even a society.

Bibliometrics, Scientometrics and Informetrics study the quantitative aspects of scientific output. Even though some researchers do not agree with this type of quantitative assessment, a critical analysis and understanding of the impact of the scientific output of our society, would be almost impossible without the aid of these indicators of scientific activity. Considering our developmental characteristics, it is necessary to use reliable markers for a review of scientific policies, because science/technology and social/economic progress - primary objectives of our society are impossible to separate.

One of the most widely used systems for measuring scientific activity is the Science Citation Index (SCI). And one of the most daring expectations of our journal is to be included in this database, which will, not only enable the continuing evaluation of the Arquivos Brasileiros de Cardiologia by the most frequently used indicators, but also facilitate the diffusion of our scientific work.

In addition to knowledge diffusion and pattern warranty, scientists receive credit for their research based on how frequently it is cited by others. To publish in journals that enable citations is one of the parameters most considered by authors when they submit their works to a scientific journal for publication.

As we improve the quality of our journal, we will attract a major number of original contributions, increasing qualitatively and quantitatively our scientific output. It is up to the Arquivos Brasileiros de Cardiologia to break through the barriers that impair the diffusion of our national scientific work, so that we can help increase the citation index of our cardiologists by the South American and the international community. Therefore, an edition of the Arquivos Brasileiros de Cardiologia in English is essential. However, since we can not fail to provide Brazilian cardiologists with a journal in Portuguese, we chose to produce a bilingual publication. After obtaining the approval of our readers and the support of the board of directors of the Brazilian Society of Cardiology, we provide in this issue of January 1999 first simultaneous publication of our journal in both Portuguese and English. Our hope is that soom our journal will be 
included in the Science Citation Index (Institute for Scientific Information), and its impact will then be measured and continuously improved. This will certainly constitute a great stimulus for publication of Brazilian scientific research in the Arquivos Brasileiros de Cardiologia, with consequent benefit to our readers and strengthening of our researchers.

Our responsability to the enhancement of Brazilian society is even more important than our duty to the Brazilian Society of Cardiology. We believe that our actions will contribute to the scientific growth of cardiology in Brazil, but we continuously reevaluate our enthusiasm with a critical spirit. We know that changes that have social or scientific impact on society are very complex and difficult to quantify. However, one fact is very clear: social and scientific changes have never been brought about by skeptics.

Fortunately cardiologists, who continuously witness major advances in science and technology, have learned not to be skeptics. We consider publication in English of the Arquivos Brasileiros de Cardiologia to be vitally important for the development of Brazilian cardiology. However, nothing would have been be accomplished without the enthusiasm of the Brazilian Society of Cardiology board of directors. These cardiologists from the board of directors, were the great motivators of these changes and deserve the merit for the success these changes may achieve.

Angelo A. V.de Paola Márcia de Melo Barbosa 